This is a pre-copy-editing, author-produced PDF of an article accepted following peer review (14 September 2017) for publication in in Environmental Values:

http: / / www.whpress.co.uk/EV.html

\title{
Spatial framing, existing associations, and climate change beliefs
}

\author{
Adrian Brügger ${ }^{1,2^{*}}$, Nicholas F. Pidgeon ${ }^{2}$ \\ ${ }^{1}$ Department of Consumer Behavior, Faculty of Business, Economics and Social Sci- \\ ences, University of Bern, Switzerland \\ ${ }^{2}$ Understanding Risk Research Group, School of Psychology, Cardiff University, United \\ Kingdom \\ * Corresponding author \\ E-Mail: adrian.bruegger@imu.unibe.ch
}




\title{
Spatial framing, existing associations, and climate change
}

\section{beliefs}

\begin{abstract}
Tailoring climate change messages to a particular spatial scale (e.g., specific country or region) is often seen as an effective way to frame communication about climate change. Yet the empirical evidence for the effectiveness of this strategy is scarce and little is known about how recipients react to spatially framed climate change messages. To learn more about the effects and usefulness of different spatial frames as a communication and engagement tool, we conducted a study in which we presented members of the general public with either a national or a global framing of climate change. In contrast to previous spatial framing studies, the present research used semi-structured interviews - rather than survey questions - to obtain rich, in-depth information about participants' views of climate change. Irrespective of the framing, participants revealed associations that were located at various spatial scales. Moreover, when participants talked about climate change, they repeatedly switched between different spatial scales, revealing patterns that were consistent with seeking to preserve existing beliefs and preferences. These findings improve our understanding of how the public represents climate change and provide a novel explanation as to why simple spatial framing often fails to achieve the anticipated effects.
\end{abstract}

\section{Keywords}

climate change, communication, framing, psychological distance, spatial representation 


\section{Introduction}

Using a specific spatial focus can potentially increase people's engagement with climate change and their motivation to act on it. For example, it is often argued that describing local, or proximal, consequences of climate change makes the issue and its consequences more salient, thereby increasing a sense of both vulnerability and personal relevance (Scannell and Gifford, 2013; Shwom, Dan, and Dietz, 2008; Reser, Bradley, and Ellul, 2014).

Although (proximal) spatial framing is frequently suggested as a strategy to increase public engagement with climate change (Hulme, 2008; Leviston, Price, and Bishop, 2014; Lorenzoni, Nicholson-Cole, and Whitmarsh, 2007; Moser, 2010; Nicholson-Cole, 2005; Weber, 2006), there is surprisingly little research that tests this hypothesis empirically. Of more concern, the majority of the existing studies fail to show a direct effect of spatially framed climate change messages on participants' willingness to tackle climate change (Altinay, forthcoming; Brügger, Morton, and Dessai, 2016; Mir et al., 2016; Rickard, Yang, and Schuldt, 2016; Schoenefeld and McCauley, 2016; Shih and Lin, forthcoming; Shwom, Dan, and Dietz, 2008; Spence and Pidgeon, 2010). ${ }^{1}$

The goal of the present research was to better understand how individuals react to dif-

\footnotetext{
${ }^{1}$ Studies that used designs other than direct comparisons between different spatial frames provide mixed evidence for the idea that focusing on local climate change may motivate people to act on climate change. For example, experiencing local extreme weather events increased people's willingness to address climate change in some studies (e.g., Demski et al., 2017; Spence et al., 2011) but not in others (Dessai and Sims, 2010; Whitmarsh, 2008). Similarly, virtual exposure to local climate impacts in a video game also has the potential of changing people's views about climate change and possible responses to it (e.g., Schroth et al., 2014).
} 
ferent framings of climate change. To achieve this goal, this article first reviews theoretical arguments for spatial framing as a public engagement tool. We then report findings from a 'qualitative experiment' (Robinson and Mendelson, 2012) in which participants received either a proximally or a distantly framed text about climate change and then participated in a semi-structured interview that focused on their beliefs, attitudes, emotions, and behaviours related to climate change.

\section{Spatial framing as a tool to engage the public}

The idea of varying the spatial frame of climate change is typically put forward in connection with the finding that people perceive climate change to be a distant phenomenon that is not immediately relevant to them (e.g., Evans, Milfont, and Lawrence, 2014; Lorenzoni et al., 2006; Scannell and Gifford, 2013; van der Linden, Maibach, and Leiserowitz, 2015). Describing climate change in spatially proximal terms (e.g., as relevant to the country where people live) is believed to counteract this perception by decreasing the psychological distance between climate change and the recipients of such messages (Evans, Milfont, and Lawrence, 2014; Leviston, Price, and Bishop, 2014). It is further argued that spatially proximal descriptions of climate change should facilitate the visualization of its consequences (Ebi and Semenza, 2008; Lorenzoni and Pidgeon, 2006). Importantly, to the extent that individuals perceive spatially close impacts as negative and care about the threatened place, people, natural environment, or symbolic meanings, proximal frames should increase personal relevance (Brügger et al., 2015; Scannell and Gifford, 2013; Shwom, Dan, and Dietz, 2008) and (emotional) concern (Evans, Milfont, and Lawrence, 2014; Reser, Bradley, and Ellul, 2014; Spence et al., 2011; Weber, 2006). Ultimately, it is expected that these processes enhance people's motivation to act (Ebi and Semenza, 2008; Evans, 
Milfont, and Lawrence, 2014; Lorenzoni, Nicholson-Cole, and Whitmarsh, 2007; Lorenzoni and Pidgeon, 2006; Shwom, Dan, and Dietz, 2008; Spence et al., 2011; Spence, Poortinga, and Pidgeon, 2012).

Perhaps surprisingly, there are also plausible arguments to be made for using a distant framing in climate change communication. First, many people in wealthy, industrialized countries believe that the most detrimental effects of climate change will occur far away (Bord, Fisher, and O'Connor, 1998; Leiserowitz, 2006; Lorenzoni et al., 2006; Lorenzoni, Nicholson-Cole, and Whitmarsh, 2007). Thus, at least for people living in relatively privileged, temperate zones, a spatially distant perspective should entail a stronger sense of urgency than a proximal perspective (cf. Spence and Pidgeon, 2010).

When anticipating the effects of proximal and distant frames, consider that their specific foci are likely to resonate to varying extents with different segments of the public. For example, one factor that could moderate the effectiveness of spatial frames is the set of values that people hold (e.g., Schwartz, 1992): People who care strongly about goals such as achievement, power, and security — that is, those who hold self-enhancing and conservative values - may be particularly receptive to proximal frames (cf. Hart and Nisbet, 2012; Hine et al., 2016; but see also Schoenefeld and McCauley, 2016) because they highlight consequences that directly threaten their goals and values (e.g., loss or damage of property).

By contrast, frames that focus on distant impacts have a less obvious connection to immediate personal interests and are therefore less likely to appeal to self-enhancing and conservative values. Instead, a focus on risks to distant places and strangers may appeal to individuals who rank altruistic and self-transcendent values highly — that is, individuals who strongly care about all people as well as about nature, and for whom equality, justice, and helpfulness are important goals (Schwartz, 1992). Given the previously established 
link between self-transcendent values and the motivation to mitigate climate change (Capstick, Pidgeon, and Henwood, 2015; Howell, 2013; Howell and Allen, 2017; Nilsson, von Borgstede, and Biel, 2004; see also Corner, Markowitz, and Pidgeon, 2014), using distant frames to appeal to people who hold such values is a promising approach.

In sum, good reasons can be advanced for framing climate change as either a proximal or distant issue. Crucially though, the effectiveness of different spatial frames is likely to depend on the audience's goals, values, and other interindividual differences (Brügger et al., 2015). This contingency on individual views and preferences may help to explain why the few quantitative studies that have aimed to empirically test the effects of different spatial frames have typically failed to show a direct effect on people's willingness to act (Altinay, forthcoming; Brügger, Morton, and Dessai, 2016; Mir et al., 2016; Rickard, Yang, and Schuldt, 2016; Schoenefeld and McCauley, 2016; Shih and Lin, forthcoming; Shwom, Dan, and Dietz, 2008; Spence and Pidgeon, 2010). (For tentative evidence of a weak indirect effect, see Jones, Hine, and Marks, 2017; Shih and Lin, forthcoming). Provided that the proportions of the public whose values align with the two different types of frames are roughly equal across experimental samples, the lack of any overall effect may simply reflect different preferences. Yet, apart from a few studies that empirically investigated the interaction between spatial frames and individual differences, and had inconclusive findings (Rickard, Yang, and Schuldt, 2016; Schoenefeld and McCauley, 2016; Wiest, Raymond, and Clawson, 2015), the literature remains silent on how, why, and when spatial framing of climate change affects people's perceptions and behaviours.

\section{The present research}

To learn more about the effects of different spatial framings, the present research adopted a bottom-up approach. Specifically, we conducted a 'qualitative experiment' (Robinson 
and Mendelson, 2012) in which, like previous quantitative spatial framing studies (Brügger, Morton, and Dessai, 2016; Mir et al., 2016; Schoenefeld and McCauley, 2016; Shwom, Dan, and Dietz, 2008; Spence and Pidgeon, 2010), participants received either a proximally or a distantly framed text about climate change. However, rather than answer survey questions, participants then took part in a semi-structured interview that focused on their beliefs, attitudes, emotions, and behaviours related to climate change. This qualitative approach allowed us to investigate individual participants' first reactions to the two framings in more detail than would be possible in quantitative experiments; importantly, this approach also made it possible to explore unanticipated reactions, or conditional responses, something that would not be possible with a pre-defined set of closed survey questions. $^{2}$

\section{Methods}

Data collection and participants. We conducted 32 semi-structured interviews with adults from the general public of Switzerland to obtain rich, in-depth information about participants' views of climate change. Interviewees were recruited through advertisements in local newspapers and by means of notice-board advertisements in local shops. To avoid recruiting a sample biased towards people who are strongly interested in and concerned about climate change, the study was advertised topic-blind as a study on written communication. As an incentive to participate, participants were offered 20 Swiss Francs (approx. $£ 14$ or US\$20). The interviews were conducted on the premises of the University of Bern,

\footnotetext{
${ }^{2}$ Individual interviews were used in the study rather than the more interactive qualitative techniques of focus groups (e.g., Bickerstaff and Simmons, 2009; Capstick, Pidgeon, and Henwood, 2015; Stoll-Kleemann, O'Riordan, and Jaeger, 2001) to ensure that we could explore each individual participant's own responses to the texts in detail, as well as to avoid the introduction of additional framings by other participants in a group.
} 
Switzerland.

Procedure. Participants were pre-screened via an online questionnaire in terms of their age, gender, education, and political orientation (Table 1). We grouped similar participants (e.g., approximately 40-year-old women with a university degree) into pairs (matched-pair design) and randomly assigned each of them to a different spatial framing. That is, one of them received a text that introduced climate change with a proximal focus, whereas the other participant read a text with a distant focus (between-group design). Upon arrival in the interview room, participants were greeted, informed about the procedure and their rights as voluntary participants, and asked to sign a consent form. They then read a short text that described climate change either in proximal or distant terms (Appendix, Textbox 1). The interview started by asking general open-ended questions about the text. The questions then gradually became more specific, asking participants how they felt and thought about the text (Appendix, Textbox 2). Towards the end of the interview, participants were asked to compare the text they had read to the alternative text that described climate change with a different spatial focus. However, we decided not to analyse this second part of the interview here because comparing the two texts forced people to adopt a multi-scalar perspective of climate change, which would have interfered with the research questions and analytical focus of the present research. Participants were then debriefed, thanked for their participation, and offered the option of taking a leaflet listing websites with additional information about climate change and ways to mitigate it. The interviews lasted for approximately 40-60 minutes (including signing the consent form and debriefing). All interviews were audio-recorded, fully transcribed, cross-checked with the audio recording, and analysed using NVivo qualitative data analytic software. Field notes were also made and used to inform the analysis. All data were treated confidentially and stored securely. 
No real names or other identifying information were entered into statistical software packages.

Spatial framing. As in previous research (Brügger, Morton, and Dessai, 2016; Shwom, Dan, and Dietz, 2008; Spence and Pidgeon, 2010), we used two texts about the causes and consequences of climate change to induce a proximal (vs. distant) perspective on climate change. In the proximal condition, the text (Appendix, Textbox 1) referred several times to geographically proximal places ('Switzerland' or names of cities) whereas in the distant condition the text referred to specific places in other countries or simply 'all over the world' or 'across the globe'. In addition, the texts included two visuals. In the distant text the spread of the 'tiger mosquito' (Aedes albopictus; see also Textbox in the Appendix) was depicted on a map of Europe (for a current version of the map, see https://ecdc.europa.eu/sites/portal/files/images/mosquitoes-maps-Aedes-albopictus-April-2017.jpg) and the projected increase in summer droughts was illustrated with a Latin American farmer holding a small corncob. The proximal text included an extract of the same map that showed only Switzerland and a Swiss farmer working in a very dry field. The content of the text was otherwise held constant.

Data analysis procedures. During the interviews it soon became obvious that participants held associations with climate change that were located at different spatial scales and that these associations made the interviews so spatially diverse and complex that it was not possible to stick to the anticipated analytical procedure of comparing participants' reactions to the proximal and distant frame. The analysis was therefore adapted to focus on participants' spatial associations with climate change, and on how and when participants changed their focus between different spatial scales.

We chose thematic analysis (Braun and Clarke, 2006; Henwood and Pidgeon, 2003) as the method for analysing the data because the analysis was not tightly bound a priori to 
any particular theory or epistemology. As such, thematic analysis is a flexible method that allows both inductive (data driven) and deductive (theory driven) analysis. We adhered to the methodological guidelines of Braun and Clarke (2006). We first coded interesting features of the data systematically across the entire data set. This included, for example, the mention of personal experiences with and anticipated consequences of climate change. Based on their prevalence in the data and their meaningfulness, coded passages that were conceptually similar were then grouped into overarching thematic categories and subcategories and refined in an iterative process (Braun and Clarke, 2006). For example, we grouped statements about heat-related health problems and worries about catching diseases from the tiger mosquito into the theme 'health-related consequences of climate change'. Refinements included adding new coding dimensions, such as the seriousness of impacts and geographic coding (Switzerland vs. other countries). Moreover, we coded whether participants linked their associations with climate change to direct, personal experiences or to external sources such as media reports or accounts from other people (indirect experiences). This differentiation was informed by previous research (Reser, Bradley, and Ellul, 2014; Spence et al., 2011; Swim et al., 2011) and chosen because it is theoretically and practically meaningful (e.g., Spence et al., 2011) and because it enabled us to examine the relationship between participants' existing associations and different ways of learning about climate change. In sum, this procedure allowed us to take stock of the contents of existing associations with climate change, locate them geographically, and examine how they are related to different ways of learning about this issue. We refer to this first overarching analytic theme as existing spatial associations with climate change.

Building on this first theme, we then centred the second overarching theme on how participants shifted the focus of attention between different spatial scales when they talked 
about climate change. This theme and its three sub-themes represent a novel analytical approach and were therefore derived in a more grounded manner. The first switching pattern captures instances where participants responded to some aspects of the text, often directly and explicitly (e.g., 'it says here ...', 'I feel like there the point is missing that'), and related them to their beliefs and preferences. Because participants often re-adjusted the texts in a way that matched their existing cognitions, we named this switching pattern reconciling frames. The second type of place switching, revealing personal meaning, captures passages in the interviews where spatial switching co-occurred with expressions of personal meaning. We used the code 'personal meaning' when participants related climate change to their personal interests, preferences, and values, either spontaneously or in response to the relevant question from our interview schedule. ('Based on what you've read, to what extent do you think climate change will affect things that are important to you personally?') The third type of place switching, constructing resilience and vulnerability, represents instances of place switching that overlapped with talk of different degrees of seriousness, vulnerability, resilience, and adaptive capacity.

\section{Results}

Our study, which was conducted in Switzerland, revealed two findings that are relevant for understanding public representations of climate change and for communications around this issue. First, irrespective of the framing, each participant held multiple associations with climate change that were anchored at both proximal and distant places. Second, during the interviews participants often switched between different spatial scales.

We will now elaborate on the content of existing spatial associations and then focus on the process of place switching and its possible functions. 


\section{Existing geographical associations with climate change}

The interviews revealed that, with only one exception, all participants talked about both proximal (Switzerland) and distant (other countries) impacts of climate change. That is, irrespective of whether they had read the text that focused on climate change in Switzerland or on the whole planet, participants complemented the spatial focus that they were exposed to with their own prior 'out of frame' associations. In short, participants offered representations of climate change that were anchored both in proximity and distance.

When participants talked about spatially specific aspects of climate change, they mainly drew on two types of information. First, they related the perspectives of others or echoed media representations of climate change (Manzo, 2010; Metag et al., 2016; Smith and Joffe, 2009). References to reports from others included statements from people's social networks. This was obvious, for example, when one person remembered conversations with friends during a recent heat wave: 'When I talked to my friends on the telephone they always said oh God it is so hot.' (I14). Participants also related the views of people they know less well. For example, when one participant talked about retreating glaciers, she conveyed the view of people with expert status and emphasized their credibility:

That's something that the custodians of mountain huts or the guides say - that certain hikes have become more difficult because the glaciers have melted away or because snowfields melted away or have become more dangerous because of rockfall. [...] That's certainly not just an experience over two years but I mean these custodians are sometimes in the hut for decades or the mountain guides see that over decades. (I17).

Participants also reported what they had learned about climate change through the media. Interviewee 16 , for example, referred to a radio broadcast when she was talking about 
glaciers: 'Or recently I just heard on the radio that within one season there is quite a, one and a half, two meters less ice, simply like that'. Similarly, many indirect experiences (Reser, Bradley, and Ellul, 2014; Swim et al., 2011) of climate change pertained to 'iconic' climate change impacts (Braasch, 2013; Brönnimann et al., 2014; O’Neill and Hulme, 2009); that is, aspects of climate change that are frequently and somewhat stereotypically used in climate change coverage. As illustrated in the above quotes, melting glaciers and heat waves were icons that often emerged when participants talked about Switzerland. Interviewees also mentioned more distant icons such as polar bears and rising sea levels: 'Let us not fool ourselves, Venice is going to sink in water some day and certain islands in the Pacific or so, Polynesia'. Although Interviewee 26 did not explicitly link this statement to external sources, the factual way she talked about these distant impacts and the absence of any personal references suggest that she had acquired this information indirectly.

Second, participants linked climate change to specific places through direct personal experiences (Reser, Bradley, and Ellul, 2014; Spence et al., 2011; Swim et al., 2011). These associations reflected what participants personally saw or did. This is obvious, for example, when Interviewee 11 explicitly connected climate change to personal experiences of glacier retreat:

I can still remember when I was a boy we went on a school trip and the Furka Glacier still reached to the pass road and today I don't know how many 100 meters you have to go back until you get to the glacier. I have only recently crossed the Furka [Pass] again and that's, well, a pitiful remnant.

Associations with climate change that were grounded in personal experiences were connected to everyday events and activities and strongly linked to various aspects of people's lives. A striking example of this is Interviewee 7's description of the 2003 heat wave, 
which disrupted her working routine and raised health concerns:

I worked in an open-plan office back then and we simply transferred the work thing into the night $[\ldots]$ I think the temperature was 42 degrees [Celsius] in that office [...] and we couldn't work anymore. I can still remember, we went to the [river] Limmat and kind of drank stuff, stood in the water, and it was still hot. Well, it is, you're not productive anymore. In terms of health I also don't find it really, well, I found it difficult. (I7)

Although associations from personal experiences were mostly located in Switzerland, there were some exceptions to this pattern. For example, Interviewee 24 commented on how high temperatures affected her on a holiday:

I'm soon, well, in the second half of life. I mean I do feel the heat. I personally struggle when (-) I have just been to Greece, well, during two days I couldn't leave the house at noon anymore, I had real panic attacks.

Other participants described experiences when living abroad. For example, Interviewee 11 highlighted the scarcity of water and efforts to conserve it in Africa: 'I just lived in countries where water was fetched from seven meters [below the ground] and I re-used every drop to irrigate papayas, well, wastewater I mean. Naturally, then you are water sensitive.'

In sum, participants held various spatially stratified associations with climate change. Some of these associations echoed stereotypical media representations of climate change and correspond to what previous research refers to as indirect experiences (Reser, Bradley, and Ellul, 2014; Swim et al., 2011) of climate change, while other associations reflected what participants personally saw, heard, or did and, as such, represent direct experiences 
of climate change (Reser, Bradley, and Ellul, 2014; Spence et al., 2011; Swim et al., 2011).

\section{Shifting the focus between different spatial scales}

The next step in our analysis focused on how and when participants switched their focus of attention between spatial scales. We identified three types of switching patterns.

Reconciling frames captures participants' tendency to identify and to either ignore or to 'adjust' aspects of the spatial framing that do not correspond to their existing climate change knowledge, beliefs, or preferences. For example, rising sea levels were only mentioned in passing in the introductory paragraph of the texts, and yet it was one of the most frequently discussed impacts of climate change that shifted the focus of attention to other countries (Switzerland is enclosed by land). Importantly, participants in both framing conditions explicitly stated that they felt that the consequences around rising sea levels had received too little attention:

I feel like there the point is missing that you also have a problem with the population when islands are submerged and [...] the living space becomes scarcer. That's totally missing in my view. I'm not sure if that's correct but that's what is passed on to me by the media: that this will be one of the biggest problems. (I5)

A contrasting example, for those participants who had read the globally framed version of the text, was the mention of retreating glaciers in other countries. Most participants simply substituted distant glaciers with Swiss glaciers when expanding on this topic without commenting on it. Others expressed surprise about the existence of glaciers in some places: 'what surprised me, where I don't have the geographic knowledge, is that there are glaciers in India' (I32). Similarly, Interviewee 12 wondered whether the mention of distant glaciers was a mistake that should be changed so that the text refers to Switzerland: 'It says here glaciers in 
India and Peru. I mean that's something that's [also] an issue in Switzerland. Well, I don't know if this is a mistake. In any case, in this section [you should] also provide examples from here [Switzerland], yes.' The objection to not mentioning Switzerland when writing about glaciers was taken to an extreme when a 64-year-old female participant banged her fist on the table and thundered:

[W]hy does it not say Switzerland? [...] in this sense a lot [in this text] is a bit far away. [...] It's all kind of, how does this concern me, well that's not my opinion but emotionally it is somehow not close enough.

Considering other comments this participant made during the interview - for example that she preferred national newspaper articles over international ones - this reaction can be seen as discontent with the mismatch between her proximally bound primary area of interest and the global focus of the text.

Proulx and colleagues (Proulx, Inzlicht, and Harmon-Jones, 2012) provide a theoretical framework that is useful for making sense of these reconciliatory processes. They argue that any experience that is inconsistent with what a person expects or desires is uncomfortable and motivates her or him to reduce the inconsistency through compensation efforts. When interpreted within this framework, discontent with the limited attention given to sea level rise, surprise about glaciers in distant countries, and aversion to a particular spatial focus can all be seen as emotional reactions to unexpected or undesired information. Similarly, reactions such as ignoring unexpected information or adding missing elements are consistent with compensatory reactions (Good and Abraham, 2007; Jonas et al., 2014; Proulx, Inzlicht, and Harmon-Jones, 2012). This interpretation suggests, as with processes described in connection with value-based and ideologically motivated reasoning (Corner, Markowitz, and Pidgeon, 2014; Kahan et al., 2012), that spatially framed climate change messages are seen through the 
lens of existing space-related cognitions.

The second type of place switching, revealing personal meaning, was driven by thoughts and feelings about things participants cared about. Most of these place switches revolved around self-interest and directed participants' focus of attention to familiar and cherished places, which were typically (although not exclusively) located in Switzerland. For example, Interviewee 20 was afraid that flooding could affect his family's pets and belongings:

When there is a lot of water in [the brook next to our house] every now and then, it is sometimes really most impressive. In particular, we then very quickly check if for example the cat is still on the other side of the brook, yeah, where's the dog. [...] These are things that might just be more impressive with age because then it is stuff you are attached to, well, now that [flood] destroys my things.

Interviewee 14 raised similar property-related concerns when talking about how decreasing snow reliability could affect the profitability of her family's holiday flat in a ski resort: 'We have a holiday home in Adelboden and we rent this chalet out and in the winter it is always well booked. What happens if you can't ski there anymore?'

Concerns about health are an additional example of meaning-based place switching. Some participants mentioned heat waves as an annoyance or even as a threat to their health and thereby shifted their focus of attention towards their living environment (i.e., Switzerland). Interviewee 28, for example, commented: 'Yeah, I think the heat in the summer, the hot summers, I think that's what frightens me most.'

This comment also shows that personal meaning was often accompanied by emotions, typically negative ones such as fear and regret connected with negative impacts. However, sometimes positive emotions, like the appreciation of threatened pastimes such as skiing 
and mountaineering, were also present: 'And yeah well in the winter it is nice to go skiing. It would be a shame if one wasn't able to do that anymore here, it's really so nice' (I25).

The thought of retreating glaciers also evoked a mixed bag of emotions, including awe and sadness: 'Our glaciers, yeah that's sad, bloody sad. About eight years ago I went to see the Aletsch Glacier for the first time and that's tremendous, really. I don't want to know how it looks like now. It's really sad when you see the grey [rock]' (I18). Importantly, this sadness did not simply stem from a sense of loss about aesthetic degradation (see also Brady, 2014, who argues that climate change poses a threat to the aesthetic value of landscapes). Some comments suggest that participants were sad because symbolic meanings and national heritage were at stake:

These glaciers belong to these mountains. [...] I learned at school which glacier is located on which mountain. And I somehow just find it sad that my children, maybe in 20 years you perhaps don't see anything anymore of the Morteratsch Glacier. Well, there's an aesthetic side to that but the most important thing is certainly $[\ldots]$ that something that came into being over such a long period of time then so quickly disappears and we humans are responsible. (I28)

Attentional shifts towards proximity were also observed when participants worried about the effect of climate change on other pastimes and interests, such as grape vines becoming more frequently infected with pests and impairing Swiss winemaking, or rising water temperatures endangering local fish species and making angling difficult, as in Interviewee 12's comment: 'I also go fishing and that is where it concerns me particularly of course, when I don't encounter any fish in certain waters anymore or not the kind of fish that I'm actually looking for, it is something that in this sense something where it affects me very directly'. 
There were also instances where personal relevance was connected to distant places, typically expressed as worry about the welfare of people in other countries or as sense that it was unfair that those who suffer the most from climate change had contributed least to causing it. To illustrate, one participant said:

What affects me more [than consequences in Switzerland] and concerns me are consequences especially in poorer countries where they simply have less funds to adapt to these changes. When the sea level rises and in Bangladesh the land surface massively decreases and where do people go then? (I17)

These findings relativize the prominent view that a personally relevant understanding of climate change mainly stems from self-interest (Schoenefeld and McCauley, 2016), and corroborate previous work that highlighted the important role of altruistic values (Corner, Markowitz, and Pidgeon, 2014; Howell, 2013; Howell and Allen, 2017).

Constructing resilience and vulnerability is the third type of place switching and captures two facets that both make climate change appear less threatening both personally and nationally. The first facet of this comprises comments that emphasize Switzerland's resilience to climate change. It was evident, for example, when participants commented that 'Switzerland is in a temperate climate zone' (I9) or that 'fortunately, we do have a bit of Alps all around' (I18). Such comments about the geographic characteristics of Switzerland can be seen as a way to foster beliefs about its resilience.

In addition to geographic arguments, participants mentioned economic and socio-political characteristics of Switzerland as further factors contributing to its resilience. This transpired, for example, when participants argued that '[i]n Switzerland you can still afford to import stuff from the poor countries, sounds brutal but that's how it is. [...] Switzerland is one of the wealthiest countries in the world' (I9), thereby suggesting that Switzerland's 
wealth would ensure continued imports of goods. Wealth was also linked to high adaptive capacity, as is evident in Interviewee 17's comment: 'here we also have the money to kind of (-) to adapt.[...] we are doing so well economically (-) well, we somehow will find a way to deal with this [climate change].'

Participants were also confident that existing public infrastructure and services such as early disaster warning systems, flood protection equipment, and emergency and rescue services (e.g., fire brigades) could be counted on to prevent, limit, or repair damage from severe weather events. This sense of confidence was evident when one participant talked about flooding and remarked: 'So in that sense it really is, you do know that there is a structure available that is able to resolve that' (I2).

Thus, the dominant impression was that the consequences of climate change in Switzerland were 'not yet existentially threatening' but rather mild or, as several participants put it, only a 'luxury problem'. Climate change was seen as something that may be annoying (e.g., spread of new mosquito species), unpleasant (e.g., worse sleep quality during hotter summers), and sad (e.g., aesthetic degradation of the mountain landscape) but not something 'extreme or dangerous'. This sense of resilience was taken to the extreme when participants spoke of Switzerland using metaphors like 'Land of Cockaigne' and 'Elysium', paradise-like places from ancient and medieval mythology where all desires are fulfilled and happiness prevails.

The second facet of constructing resilience and vulnerability was demonstrated in comments that used the same type of arguments but stressed the vulnerability of distant places. Participants identified places that they saw as particularly vulnerable. For example, droughts and water scarcity were risks that participants located in distant 'desert nations' or 'in Africa'. Because these places already suffered from water scarcity and droughts, the outlook of further decreases in water availability was seen as particularly problematic: 
'that's bad when they have even less water (-) and already need to pump it up and the children who don't have enough food and not even water. That's why it is not good when it becomes even hotter there' (I24).

The notion that these impacts are 'bad' / 'not good' suggests that this type of commentary may be influenced by underlying values, and hints at the possible involvement of feelings such as worry and empathy. These feelings were explicitly expressed by another participant who commented on the risks to distant coastal areas:

Well, I'm mainly worried about those who come [future generations]

(-) The sea level is rising. In Holland they are frequently trying to reclaim land and to seal themselves off from the sea. And Bangladesh or large parts of Bangladesh may someday not exist anymore. [...] Bangladesh, when there are floods, then really very very much is submerged with many deaths. (I14)

Thus, and similarly to previous research (e.g., Bord, Fisher, and O'Connor, 1998; Leiserowitz, 2006; Lorenzoni and Pidgeon, 2006), these comments about droughts and rising sea levels suggest that participants perceived climate change as a threat that is more severe and serious in distant places.

Another topic that was mentioned when participants talked about the vulnerability of distant places was their socio-political and infrastructural situation. For example, Interviewee 21 draw attention to economic difficulties and the negative effects of armed conflicts: 'Well, certainly Africa [will be affected by climate change] (-) I think Africa, Asia, the deserts, those people, poor people, naturally, the less well-off, the Third World, there, or war-torn countries $[\ldots]$ where everything is damaged, where they have to import everything.' Similarly, it was believed that foreign governments were not doing enough to adapt to climate change: 
'There [in Africa] the government is required to take structural measures, to build a sewage system [...] There they probably need to become a bit more active than we here in Switzerland (-) and the willingness must be there, that they want to do that, right? [...] That's kind of the problem, yes, that's worrying me a bit in the sense that the government there is perhaps isn't doing enough, development aid as such on site.' (I20)

Moreover, the perception that other countries were more vulnerable than Switzerland was intensified by doubts about their adaptive capacity, for example, 'because they maybe don't have the possibility to irrigate [their fields]' (I8).

A striking feature of the tendency to construct resilience and vulnerability was that participants often directly contrasted impacts beyond the border with consequences in Switzerland:

In a desert region, where it is supposed to become even hotter and even drier, there it is more real. But in Switzerland, maybe the consequences come a bit across like, well, it is maybe just a bit too comfortable, simply because then, ok, it is nice and hot and then you go swimming. (I2)

Similarly, another participant noted that: 'In Switzerland we are actually in the pole position, we are directly on the water, it [water scarcity] won't affect us [...]. The further out you go, Africa or areas like that, [...] there it will be a problem' (I29).

One way of making sense of constructing resilience and vulnerability is to take this pattern at face value; that is, as a direct reflection of what participants believe and know about climate change at different spatial scales. An alternative view is to interpret the ap- 
parently factual arguments as a manifestation of more active and motivated processes (Potter and Wetherell, 1987). More specifically, previous research showed that many people are not prepared to acknowledge spatially proximal risks and instead project them into the distance (Bickerstaff and Simmons, 2009; Gifford et al., 2009; Schultz et al., 2014). As such, emphasizing other places' vulnerability and Switzerland's resilience can also be seen as distancing a risk (Bickerstaff and Simmons, 2009) or, more generally speaking, as evidence of defensive processing (Good and Abraham, 2007; Jonas et al., 2014; Proulx, Inzlicht, and Harmon-Jones, 2012). Although both interpretations are plausible in principle, there are some inconsistencies in both. While it may be correct that Switzerland is less vulnerable to climate change than many other countries (ND-GAIN, 2017), Switzerland still faces relevant consequences (Brönnimann et al., 2014), which make the sense of resilience that emerged from this aspect of participants' discourse seem overly optimistic. Regarding the second interpretation, theory holds that defensive processing is typically accompanied by negative emotions (Good and Abraham, 2007; Jonas et al., 2014; Proulx, Inzlicht, and Harmon-Jones, 2012). However, participants rarely articulated intense emotions, even when the interviewer asked them directly about emotions related to climate change. 


\section{Discussion}

This research revealed two important space-related perspectives that become evident when people talk about climate change. First, all participants held multiple associations with climate change, some of which were located close to where they live, while others were geographically distant. (See, for example, Interviewee 11's personal experiences of glacier retreat in Switzerland and water scarcity in Africa, or Interviewee 14's concern that her family will not be able to rent out their holiday home in the Swiss mountains in the future and her worries about the negative effects of rising sea levels in the Netherlands and Bangladesh.) Second, participants spontaneously drew on their spatially stratified associations and switched repeatedly between proximal and distant aspects of climate change.

The finding of the spatially complex and fluid representation of climate change is relevant for theory because it improves our understanding of how members of the public represent climate change: namely, as a phenomenon that is simultaneously proximal and distant. As such, our results corroborate the findings of a previous reanalysis of qualitative data indicating that people represent risks in general (Bickerstaff and Simmons, 2009) in a spatially complex manner that comprises both proximity and distance. Moreover, our qualitative approach complements the results from a quantitative survey that found — based on four closed questions - similar spatially stratified perceptions of climate-related risks (Spence, Poortinga, and Pidgeon, 2012). It is also interesting to note that this multi-scalar perspective is consistent with theoretical discussions of taking a 'glocal' perspective on climate change, meaning that climate change should be seen and tackled as a phenomenon that is both local and global (Gupta, Leeuw, and Moel, 2007).

The most pressing question that follows from our findings concerns their implications for the use of spatially focused climate change communication. Participants' direct reac- 
tions to the spatially framed message — that is, their tendency to ignore or adjust unexpected spatial information or to add missing geographic aspects — suggest that existing associations act as a lens that adjusts surprising or unexpected information (Good and Abraham, 2007; Jonas et al., 2014; Proulx, Inzlicht, and Harmon-Jones, 2012), which might attenuate the effect of the spatial framing or prevent people from adopting the intended spatial perspective altogether. Moreover, it is possible that variations in individual beliefs and preferences and the focal shifts that these cognitions trigger could also diminish the effectiveness of spatially framed messages in eliciting the intended focus. Taken together, existing spatial associations and the processes around them have the potential to considerably dilute the effectiveness of spatial framing. Such active processing may more generally help to explain why spatially framing climate change often fails to produce the intended effects (Altinay, forthcoming; Brügger, Morton, and Dessai, 2016; Mir et al., 2016; Rickard, Yang, and Schuldt, 2016; Schoenefeld and McCauley, 2016; Shih and Lin, forthcoming; Shwom, Dan, and Dietz, 2008; Spence and Pidgeon, 2010).

At least two additional considerations follow in terms of using spatial framing. First, the present research compared people's reactions to national and global frames. It would be interesting for theory and practice to systematically vary the spatial distance of climate change (e.g., neighbourhoods, towns, regions, nations, international, global; see also Devine-Wright, Price, and Leviston, 2015) and explore how people react to these frames. Second, it could be questioned whether it is a good idea in the first place to make people focus on a restricted geographical range of climate change impacts. Whatever the focus, some important aspect of global climate change will be missing, leading to a loss of message credibility at best (Alter and Oppenheimer, 2009) and to message rejection at worst (Good and Abraham, 2007; Jonas et al., 2014; Proulx, Inzlicht, and Harmon-Jones, 2012). An alternative approach that could be tested in future research is to communicate climate 
change in a way that incorporates relevant elements from multiple scales (or frames, Bernauer and McGrath, 2016), thus offering the best of different worlds (e.g., conveying a sense of severity as well as personal relevance, Spence and Pidgeon, 2010). It is interesting to note that some participants spontaneously came up with such mixed frames themselves, suggesting that this approach is likely to resonate better with the public than a strictly compartmentalised depiction of climate change.

A possible limitation of this research was that participants were not strictly statistically representative of the general population of Switzerland. Such representativeness is an important consideration when one has large participant samples and wishes to make generalised claims about the prevalence of specific views and behaviours in the population. However, the purpose of this study was to explore in detail the psychological processes and spontaneous associations underlying people's reactions to the two different spatial framings. In this respect, sampling has to be driven by qualitative rather than statistical considerations (e.g., Curtis et al., 2000), with the principal aim of recruiting as diverse a set of prior perspectives as possible, representing people drawn from a broad cross-section of Swiss society. We believe that our sample did achieve enough diversity to allow us to identify and describe different types of reactions among the general public in Switzerland.

Moreover, at least two findings from previous research suggest that one can expect to find comparable spatially stratified associations with climate change and similar switching processes in other national and international samples. First, people are typically exposed to a spatially diverse range of climate change frames through media coverage (Hart and Feldman, 2014; Olausson, 2009; O’Neill, 2013). Second, research on perceptions of (Metag et al., 2016) and associations with climate change in Switzerland and other Western European and North American countries (Imper and Walraf, 2009; Leiserowitz, 2006; Lorenzoni et al., 2006) also points to spatially comprehensive representations. It therefore seems 
plausible that the findings described here can be replicated with other national and international samples. Nevertheless, replicating the present findings with a larger, more representative sample would be useful to learn more about the prevalence of specific types of reactions to varying spatial framings, and allow exploration of any interaction with people's underlying worldviews and values.

One aspect of the present findings that could prove more difficult to generalize to other socio-political contexts is the tendency to construe one's own country as a safe place. To the extent that this pattern is consistent with objective assessments of resilience, which rank Switzerland among the most resilient countries in the world (ND-GAIN, 2017), people in other countries that are objectively less resilient should feel more vulnerable and tend less to think of their country as a safe place. However, substantial evidence from various socio-political contexts points to a general tendency to believe that one's own environment is in a better condition and is safer than other places (Gifford et al., 2009; Schultz et al., 2014). Thus, it is possible that people in objectively more vulnerable places will also tend to think of themselves as safe. Empirically exploring how people in more vulnerable regions of the world spatially represent climate change and how they react to spatial frames could be a fruitful avenue for future research.

\section{Conclusion}

The present research demonstrates how geographical associations, beliefs, and preferences that members of the public hold about climate change can lead to active processing of climate change messages in a way that, in part, reaffirms and preserves existing cognitions. In particular people can relate to, and indeed actively construct, both local and distant perspectives in response to framing information. Although this pattern should not be taken to 
imply that spatial framing is doomed to be ineffective as a means of prompting engagement, it cautions researchers, climate communicators, and policy makers against assuming that climate change can ever be spatially 'frameable' in any simple, or singular way. It also provides a novel explanation as to why previous attempts to use different spatial foci as a tool to increase engagement with climate change have had little to no effect. We hope that these insights will inform both research and practice, and provide a fresh perspective on how the public makes sense of climate change and on the role that spatial cognition plays in this. 


\section{Acknowledgments}

We thank Stuart Capstick for his comments and advice on the design of the study and for his comments on earlier versions of this manuscript. AB was supported by a grant from the Swiss National Science Foundation (grant P2SKP1_158706). NP was supported by the Social and Economic Research Council (grant ES/M005135/1). 


\section{References}

Alter, A.L. and D.M. Oppenheimer. 2009. 'Uniting the tribes of fluency to form a metacognitive nation'. Personality and Social Psychology Review 13(3): 219-35.

Altinay, Z. (forthcoming). 'Visual communication of climate change: Local framing and place attachment'. Coastal Management.

Bernauer, T. and L.F. McGrath. 2016. 'Simple reframing unlikely to boost public support for climate policy'. Nature Climate Change 6(7): 680-3.

Bickerstaff, K. and P. Simmons. 2009. ‘Absencing/presencing risk: Rethinking proximity and the experience of living with major technological hazards'. Geoforum 40(5): 864-72.

Bord, R.J., A. Fisher and R.E. O’Connor. 1998. 'Public perceptions of global warming: United States and international perspectives'. Climate Research 11(1): 75-84.

Braasch, G. 2013. 'Climate change: Is seeing believing?' Bulletin of the Atomic Scientists 69(6): 33-41.

Brady, E. 2014. 'Aesthetic value, ethics and climate change'. Environmental Values 23(5): $551-70$.

Braun, V. and V. Clarke. 2006. 'Using thematic analysis in psychology'. Qualitative Research in Psychology 3(2): 77-101.

Brönnimann, S. et al. 2014. 'Climate change in Switzerland: A review of physical, institutional, and political aspects'. Wiley Interdisciplinary Reviews: Climate Change 5(4): $461-481$

Brügger, A. et al. 2015. 'Psychological responses to the proximity of climate change'. Nature Climate Change 5(12): 1031-7.

Brügger, A., T.A. Morton and S. Dessai. 2016. "Proximising” climate change reconsidered: A construal level theory perspective'. Journal of Environmental Psychology 46: 12542. 
Capstick, S.B., N.F. Pidgeon and K. Henwood. 2015. 'Stability and change in British public discourses about climate change between 1997 and 2010'. Environmental Values 24(6): 725-53.

Corner, A., E. Markowitz and N.F. Pidgeon. 2014. 'Public engagement with climate change: The role of human values'. Wiley Interdisciplinary Reviews: Climate Change 5(3): $411-22$.

Curtis, S. et al. 2000. 'Approaches to sampling and case selection in qualitative research: Examples in the geography of health'. Social Science \& Medicine 50(7-8): 1001-14.

Demski, C. et al. 2017. 'Experience of extreme weather affects climate change mitigation and adaptation responses'. Climatic Change 140(2): 149-64.

Dessai, S. and C. Sims. 2010. 'Public perception of drought and climate change in southeast England'. Environmental Hazards 9(4): 340-57.

Devine-Wright, P., J. Price and Z. Leviston. 2015. 'My country or my planet? Exploring the influence of multiple place attachments and ideological beliefs upon climate change attitudes and opinions'. Global Environmental Change 30: 68-79.

Ebi, K.L. and J.C. Semenza. 2008. 'Community-based adaptation to the health impacts of climate change'. American Journal of Preventive Medicine 35(5): 501-7.

Evans, L., T.L. Milfont and J. Lawrence. 2014. 'Considering local adaptation increases willingness to mitigate'. Global Environmental Change 25: 69-75.

Gifford, R. et al. 2009. 'Temporal pessimism and spatial optimism in environmental assessments: An 18-nation study'. Journal of Environmental Psychology 29(1): 1-12.

Good, A. and C. Abraham. 2007. 'Measuring defensive responses to threatening messages: A meta-analysis of measures'. Health Psychology Review 1(2): 208-29.

Gupta, J., K. van der Leeuw and H. de Moel. 2007. 'Climate change: a "glocal” problem requiring "glocal” action'. Environmental Sciences 4(3): 139-48. 
Hart, P.S. and L. Feldman. 2014. 'Threat without efficacy? Climate change on U.S. network news'. Science Communication 36(3): 325-51.

Hart, P.S. and E.C. Nisbet. 2012. 'Boomerang effects in science communication: How motivated reasoning and identity cues amplify opinion polarization about climate mitigation policies'. Communication Research 39(6): 701-23.

Henwood, K. and N. Pidgeon. 2003. 'Grounded theory in psychological research'. In P.M. Camic et al. (eds.), Qualitative Research in Psychology: Expanding Perspectives in Methodology and Design, pp. 131-155. Washington, DC: American Psychological Association.

Hine, D.W. et al. 2016. 'Preaching to different choirs: How to motivate dismissive, uncommitted, and alarmed audiences to adapt to climate change?' Global Environmental Change 36: 1-11.

Howell, R.A. 2013. 'It's not (just) “the environment, stupid!” Values, motivations, and routes to engagement of people adopting lower-carbon lifestyles'. Global Environmental Change 23(1): 281-290.

Howell, R.A. and S. Allen. 2017. 'People and planet: Values, motivations and formative influences of individuals acting to mitigate climate change'. Environmental Values 26(2): 131-55.

Hulme, M. 2008. 'Geographical work at the boundaries of climate change'. Transactions of the Institute of British Geographers 33(1): 5-11.

Imper, I. and U. Walraf. 2009. Risikowahrnehmung, Assoziationen und Handlungsbereitschaft bezüglich Klimawandel [Risk Perception, Associations, and Willingness to Act in the Context of Climate Change]. Zürich: University of Zürich. 
Jonas, E. et al. 2014. 'Threat and defense: From anxiety to approach'. In J. M. Olson and M. P. Zanna (eds.), Advances in Experimental Social Psychology 49. Cambridge, Massachusetts: Academic Press.

Jones, C., D.W. Hine and A.D.G. Marks. 2017. 'The future is now: Reducing psychological distance to increase public engagement with climate change'. Risk Analysis 37(2): $331-41$.

Kahan, D.M. et al. 2012. 'The polarizing impact of science literacy and numeracy on perceived climate change risks'. Nature Climate Change 2(10): 732-735.

Leiserowitz, A. 2006. 'Climate change risk perception and policy preferences: The role of affect, imagery, and values'. Climatic Change 77: 45-72.

Leviston, Z., J. Price and B. Bishop. 2014. 'Imagining climate change: The role of implicit associations and affective psychological distancing in climate change responses'. European Journal of Social Psychology 44(5): 441-54.

van der Linden, S., E. Maibach and A. Leiserowitz. 2015. 'Improving public engagement with climate change: Five "best practice" insights from psychological science'. Perspectives on Psychological Science 10(6): 758-63.

Lorenzoni, I. et al. 2006. 'Cross-national comparisons of image associations with "global warming" and "climate change" among laypeople in the United States of America and Great Britain'. Journal of Risk Research 9: 265-81.

Lorenzoni, I., S. Nicholson-Cole and L. Whitmarsh. 2007. 'Barriers perceived to engaging with climate change among the UK public and their policy implications'. Global Environmental Change 17: 445-59.

Lorenzoni, I. and N.F. Pidgeon. 2006. 'Public views on climate change: European and USA perspectives'. Climatic Change 77: 73-95. 
Manzo, K. 2010. 'Beyond polar bears? Re-envisioning climate change'. Meteorological Applications 17: 196-208.

Metag, J. et al. 2016. 'Perceptions of climate change imagery evoked salience and self-efficacy in Germany, Switzerland, and Austria'. Science Communication 38(2): 197-227.

Mir, H.M. et al. 2016. 'The impact of outcome framing and psychological distance of air pollution consequences on transportation mode choice'. Transportation Research Part D: Transport and Environment 46: 328-38.

Moser, S.C. 2010. 'Communicating climate change: History, challenges, process and future directions'. Wiley Interdisciplinary Reviews: Climate Change 1: 31-53.

ND-GAIN. 2017. 'ND-GAIN country index rankings'. ND-GAIN Country Index Rankings, http://index.gain.org/ranking (accessed 26 July 2017)

Nicholson-Cole, S. 2005. 'Representing climate change futures: A critique on the use of images for visual communication'. Computers, Environment and Urban Systems 29(3): $255-73$

Nilsson, A., C. von Borgstede, and A. Biel. 2004. 'Willingness to accept climate change strategies: The effect of values and norms'. Journal of Environmental Psychology 24: $267-77$.

Olausson, U. 2009. 'Global warming-global responsibility? Media frames of collective action and scientific certainty'. Public Understanding of Science 18(4): 421-36.

O’Neill, S. and M. Hulme. 2009. 'An iconic approach for representing climate change'. Global Environmental Change 19(4): 402-10.

O’Neill, S.J. 2013. 'Image matters: Climate change imagery in US, UK and Australian newspapers'. Geoforum 49: 10-9.

Potter, J. and M. Wetherell. 1987. Discourse and Social Psychology: Beyond Attitudes and Behaviour. London: Sage. 
Proulx, T., M. Inzlicht, and E. Harmon-Jones. 2012. 'Understanding all inconsistency compensation as a palliative response to violated expectations'. Trends in Cognitive Sciences 16(5): 285-91.

Reser, J.P., G.L. Bradley, and M.C. Ellul. 2014. 'Encountering climate change: "Seeing” is more than "believing". Wiley Interdisciplinary Reviews: Climate Change 5(4): 52137.

Rickard, L.N., Z.J. Yang, and J.P. Schuldt. 2016. 'Here and now, there and then: How “departure dates" influence climate change engagement'. Global Environmental Change 38: $97-107$.

Robinson, S. and A.L. Mendelson. 2012. 'A qualitative experiment research on mediated meaning construction using a hybrid approach'. Journal of Mixed Methods Research 6(4): 332-47.

Scannell, L. and R. Gifford. 2013. 'Personally relevant climate change: The role of place attachment and local versus global message framing in engagement'. Environment and Behavior 45(1): 60-85.

Schoenefeld, J.J. and M.R. McCauley. 2016. 'Local is not always better: The impact of climate information on values, behavior and policy support'. Journal of Environmental Studies and Sciences 6(4): 724-732.

Schroth, O. et al. 2014. 'Visual climate change communication: From iconography to locally framed 3D visualization'. Environmental Communication: A Journal of Nature and Culture 8(4): 413-32.

Schultz, P.W. et al. 2014. 'Cross-cultural evidence for spatial bias in beliefs about the severity of environmental problems'. Environment and Behavior 46(3): 267-302. 
Schwartz, S.H. 1992. 'Universals in the content and structure of values: Theoretical advances and empirical tests in 20 countries'. Advances in Experimental Social Psychology 25: $1-65$.

Shih, T.-J. and C.-Y. Lin. (forthcoming). 'Developing communication strategies for mitigating actions against global warming: Linking framing and a dual processing model'. Environmental Communication.

Shwom, R., A. Dan and T. Dietz. 2008. 'The effects of information and state of residence on climate change policy preferences'. Climatic Change 90: 343-58.

Smith, N. and H. Joffe. 2009. 'Climate change in the British press: The role of the visual'. Journal of Risk Research 12(5): 647-63.

Spence, A. and N.F. Pidgeon. 2010. 'Framing and communicating climate change: The effects of distance and outcome frame manipulations'. Global Environmental Change 20: $656-67$.

Spence, A. et al. 2011. 'Perceptions of climate change and willingness to save energy related to flood experience'. Nature Climate Change 1(1): 46-9.

Spence, A., W. Poortinga, and N.F. Pidgeon. 2012. 'The psychological distance of climate change'. Risk Analysis 32(6): 957-972.

Stoll-Kleemann, S., T. O’Riordan and C.C. Jaeger. 2001. 'The psychology of denial concerning climate mitigation measures: evidence from Swiss focus groups'. Global Environmental Change 11(2): 107-17.

Swim, J.K. et al. 2011. 'Psychology's contributions to understanding and addressing global climate change'. American Psychologist 66(4): 241-50.

Weber, E.U. 2006. 'Experience-based and description-based perceptions of long-term risk: Why global warming does not scare us (yet)'. Climatic Change 77: 103-20. 
Whitmarsh, L. 2008. 'Are flood victims more concerned about climate change than other people? The role of direct experience in risk perception and behavioural response'. Journal of Risk Research 11: 351-74.

Wiest, S.L., L. Raymond and R.A. Clawson. 2015. 'Framing, partisan predispositions, and public opinion on climate change'. Global Environmental Change 31: 187-98. 


\section{Tables}

Table 1.

Demographic characteristics of participants

\begin{tabular}{|c|c|c|}
\hline & Frequency & $\%$ \\
\hline \multicolumn{3}{|l|}{ Gender } \\
\hline Female & 20 & 62.5 \\
\hline Male & 12 & 37.5 \\
\hline \multicolumn{3}{|l|}{ Age } \\
\hline $16-24$ & 3 & 9.4 \\
\hline $25-44$ & 11 & 34.4 \\
\hline $45-64$ & 12 & 37.5 \\
\hline 65 and over & 6 & 18.8 \\
\hline \multicolumn{3}{|l|}{ Qualifications } \\
\hline Primary education (typically until the age of 12) & 1 & 3.1 \\
\hline Secondary education I (typically until the age of 16) & 1 & 3.1 \\
\hline $\begin{array}{l}\text { Apprenticeship or technical vocational school } \\
\text { (typically until the age of } 20 \text { ) }\end{array}$ & 8 & 25.0 \\
\hline $\begin{array}{l}\text { Secondary education II / A-Levels } \\
\text { (typically until the age of 20) }\end{array}$ & 4 & 12.5 \\
\hline Higher technical vocational school & 3 & 9.4 \\
\hline Tertiary education (e.g., University) & 15 & 46.9 \\
\hline \multicolumn{3}{|l|}{ Political orientation } \\
\hline far left & 2 & 6.3 \\
\hline left & 5 & 15.6 \\
\hline slightly left & 11 & 34.4 \\
\hline middle & 8 & 25.0 \\
\hline slightly right & 4 & 12.5 \\
\hline right & 1 & 3.1 \\
\hline far right & 1 & 3.1 \\
\hline
\end{tabular}




\title{
Appendix
}

\author{
Textbox 1 .
}

Spatial framing of climate change (distant condition in italics).

\begin{abstract}
What is climate change?
"Climate" is defined as the average weather experienced in a region over a long period (usually 30 years). "Climate change" refers to changes in the Earth's temperature and other climate-related phenomena (e.g., rainfalls, wind) since the Industrial Revolution (approx. 1850-1900).

According to climate scientists there is no doubt that the climate is changing: Since the Industrial Revolution the average temperatures in Switzerland (average global temperatures) have risen by about $1{ }^{\circ} \mathrm{C}$. This warming is associated with other climatic changes, like the decrease of snow and ice in various places in Switzerland (various regions around the world) or the rise in sea levels.
\end{abstract}

\section{Causes of climate change}

The current state of research shows that these observed changes in climate cannot be explained if only natural causes are considered. Climate scientists agree that the climatic changes in the last 150 years were caused by humans. A central cause for the warming of the atmosphere is the emission of greenhouse gases (e.g., carbon dioxide, methane). A substantial proportion of these emissions are caused by deforestation and burning fossil fuels (e.g., oil and coal). Closer inspection further shows that greenhouse gases are mainly emitted in connection with food production, the heating of buildings, and transport.

\section{What are the consequences of climate changes for Switzerland (the world)?}

Experts predict that (average global) temperatures in Switzerland will rise further between $1^{\circ} \mathrm{C}$ and $8^{\circ} \mathrm{C}$ by 2100 . Such temperature rises will have impacts on humans, animals, and plants:

- Heat waves like the one in 2003 - the hottest summer since 1540 - will become the new normal in Switzerland (in Europe) by 2040. The effects of heat waves will be felt particularly in large cities like Zürich, Basel, and Geneva (London, New York, or Tokyo), where buildings and streets absorb and radiate the energy from the sun.

- Heat waves are not just unpleasant - they also represent a threat to human health, especially for older people and small children. To illustrate, during the heat wave in 2003 approximately 5\% more people died in Switzerland (in Europe) than in an average summer.

- Droughts and water scarcity will occur more frequently, especially in the Swiss plateau, the Valais, and the Ticino (Central America, Southern Africa, and Southeast Asia). As a consequence, agriculture is threatened by harvest losses and private individuals will need to reduce their water consumption.

- While summers will become hotter and drier, there will be more frequent and more intense rainfalls in winters and springs than today. This also entails more frequent flooding and rising groundwater, which, in turn, causes damage to buildings and public infrastructure (e.g., railway).

- Increasing average temperatures will also lead to the melting of glaciers (e.g., in the Bernese Oberland or in the Valais) (e.g., in India or Peru). By the end of this century, as much as $90 \%$ of the Swiss (world's) glaciers will be gone completely. In the long term, the disappearance of glaciers will have mostly negative consequences. These consequences include the absence of tourists, increasing natural hazards (e.g., formation and sudden discharging of glacial lakes), and, ultimately, water scarcity.

- Climate change also means that some indigenous species become extinct because their habitats disappear or because they are superseded by alien species, who can cope better with the new environmental conditions.

- The spread of foreign species also affects people. For example, the tiger mosquito, that is established in Ticino (Italy) and has already been observed in northern parts of Switzerland (Europe), is a threat to human health because it can transmit dangerous tropical diseases.

All in all, climate change will have many different impacts on the natural and human environment. Some of these consequences may seem positive at first glance (i.e., increased warmth in currently cold regions). But, the majority of changes will be negative.

\section{Steps against climate change}

In order to successfully act against climate change, it is necessary for nations to commit to a climate-friendly handling of the planet Earth and for politicians to establish a climate-friendly (macroeconomic) context.

Irrespective of what politicians do, everyone can contribute to protecting the climate. Indirectly this is possible by voting for politicians who stand up for protecting the climate. But people can also become active as private persons and reduce their greenhouse gas emissions by as much as $20 \%$ through simple actions in everyday life - without any noteworthy costs or losses in prosperity. For example, people can use energy efficient electric appliances or reduce the indoor temperature during the winter. A reduction of the room temperature by only 1 degree decreases the energy consumption of one's heating system by $6 \%$. 
People who are willing to change their life more substantially, for example, by reducing their meat consumption or the numbers of flights they take, or by not owning a car, can reduce their greenhouse gas emissions by $40 \%$ or more. When considering that private households cause approximately $35 \%$ of all greenhouse gas emissions, it becomes clear that such behaviour changes can make a substantial contribution to protecting the climate! 


\section{Textbox 2 .}

Interview schedule

Questions asked during the interview

1) To start with, I'd be interested in knowing how it was for you to read this text. What is your first spontaneous impression of the text?

2) Now, I would appreciate if you could tell me what you liked and disliked about the text.

3) The text describes possible consequences of climate change. What did you like and dislike about the examples? How much did you like the examples that are mentioned in the text?

4) If one likes and dislikes something, then there are often more specific feelings involved, that can be described more closely. How would you describe your feelings when you read the text?

5) When you think back to the feelings you had when you were reading the text, what overall emotional impression did the text create?

6a) [When negative feelings were reported] I'd like to briefly come back to some of the feelings you mentioned. What would help you to reduce or to get completely rid of the negative feelings you experienced?

6b) What can you personally do to cope with these feelings? Just tell me what actions or reactions spontaneously come to mind.

7) When you think about climate change as it was described in the text, how serious or harmless a problem is climate change in your opinion?

8) Based on what you've read, to what extent do you think climate change will affect things that are important to you personally?

9) One aspect that interviewees have different opinions about concerns the familiarity of the text. Some people think this text is old news and that they have heard it all before. Others find it interesting and revealing. How about you?

10) How believable and convincing did you find the text?

11) When someone writes a text, the author usually wants to achieve something. What do you imagine is the goal of this text? What effect is the text intended to achieve among its readers? 